\title{
Patenting Alloys: The Journey is the Destination
}

\section{Jin-Won Jung}

Developing a new alloy can take serious efforts. Making prototypes, testing the material properties, and qualifying the alloy for commercial applications all require time, money, and patience. Suppose the developed alloy was not protected by patents. All could be lost if a competitor reverse-engineers the alloy-a single wet-chemistry test could reveal the alloy composition.

A patent can effectively protect the new alloy. So how should one go about patenting an alloy? One of the ways to understand patenting is to view it as a process, where the journey is almost as important as the destination. If the destination of the patenting journey is an issued patent, the journey reaching the destination would include keeping a research notebook, reporting an invention disclosure, and helping to write a good patent application.

The first stop on the patenting journey is to record an idea in a research notebook. The rule is simple: If you have an idea, write it down, sign and date it, and have a colleague also sign and date it. Why the formality? Because one day, the research notebook may be used as evidence in court to show that you came up with the idea first. Try to review your research notebook at least every week or so.

If the idea seems worth pursuing further, the next stop on the patenting journey is to, in a timely manner, report an invention disclosure. The report can be made to an in-house legal department patent attorney or agent. The invention disclosure should include, among other things, a description of the idea (based on the research notebook), drawings, and test results - not just for the prototypes that worked, but also for the ones that did not. Unsuccessful prototypes can be helpful to show that your invention was not obvious. Also include other patents and publications that you consider relevant, as well as any public presentations, publications, or sales of the invention. A good invention disclosure helps define the invention and assess whether or not to proceed with filing a patent application.

The invention disclosure can be used to draft the patent application. It may be helpful to understand some basic aspects of a patent to help draft a good patent application. A patent can be viewed as a contract between the inventor and the government. The inventor is granted, for a limited term, the right to exclude others from mak-

\section{The invention \\ disclosure should \\ include, among other \\ things, a description of \\ the idea (based on the \\ research notebook), \\ drawings, and test \\ results-not just for \\ the prototypes that \\ worked, but also for \\ the ones that did not.}

ing, using, or selling the invention. In return, the inventor must disclose the invention to the public, meeting specific tests. That disclosure is what goes into the patent application.

To get a patent, the patent application must show that the invention is useful, new, and non-obvious. For an alloy, being useful is usually not an issue. "New" means that the invention was not previously known or used by the public, or described in other pat- ents and publications. "Non-obvious" means that at the time the invention was made, a person having ordinary skills in the art would not have considered the invention obvious. A well-kept research notebook and invention disclosure can help establish these factors in the patent application.

As with any document, a patent should be written with the audience in mind. To fellow metallurgists, the patent could provide a technical description of the invented alloy. If the patent ends up being the subject of a lawsuit, the patent may also serve as a legal document for a judge. In the lawsuit, the patent may also need to educate a jury. And for potential licensing, the patent may serve as an advertisement of the technology. To draft a good patent application, the various audiences need to be considered, so plan aheadit takes time to skillfully describe the invention.

Perhaps most importantly, the patent application should define the metes and bounds of the invention. It thus becomes important to disclose not only the composition of a successful prototype, but to contemplate alternatives as well. Again, think ahead of time-you may want to explore the composition space around your invention on computer, with specimens, or both.

In sum, patenting may be best viewed as a process where the journey is almost as important as the destination. To write a good patent application, it is helpful to diligently keep a research notebook and timely report an invention disclosure along the way. A successfully issued patent can be an important asset to protect the new alloy on which you worked so hard.

Jin-Won Jung is a patent attorney with Michae Best \& Friedrich LLP in Chicago, Illinois. 